Article

\title{
Influence of Chiral Compounds on the Oxygen Evolution Reaction (OER) in the Water Splitting Process
}

\author{
Mirko Gazzotti ${ }^{1}$, Andrea Stefani ${ }^{1}$, Marco Bonechi ${ }^{2}$, Walter Giurlani ${ }^{2}{ }^{(1)}$, \\ Massimo Innocenti ${ }^{2, *(D)}$ and Claudio Fontanesi ${ }^{1, *}$ (iD \\ 1 Department of Engineering 'Enzo Ferrari', University of Modena and Reggio Emilia, Via Vivarelli 10, \\ 41125 Modena, Italy; gazzotti.mirko@gmail.com (M.G.); 181878@studenti.unimore.it (A.S.) \\ 2 Department of Chemistry, University of Firenze, via della Lastruccia 3, 50019 Sesto Fiorentino, Firenze, Italy; \\ marco.bonechi@hotmail.it (M.B.); walter.giurlani@unifi.it (W.G.) \\ * Correspondence: m.innocenti@unifi.it (M.I.); claudio.fontanesi@unimore.it (C.F.)
}

Academic Editor: Mark Symes

Received: 2 July 2020; Accepted: 27 August 2020; Published: 1 September 2020

\begin{abstract}
Results are presented concerning the influence on the water splitting process of enantiopure tartaric acid present in bulk solution. Stainless steel and electrodeposited nickel are used as working electrode (WE) surface. The latter is obtained by electrodeposition on the two poles of a magnet. The influence and role played by the chiral compound in solution has been assessed by comparing the current values, in cyclic voltammetry $(\mathrm{CV})$ experiments, recorded in the potential range at which oxygen evolution reaction (OER) occurs. In the case of tartaric acid and nickel WE a spin polarization of about $4 \%$ is found. The use of the chiral environment (bulk solution) and ferromagnetic chiral $\mathrm{Ni}$ electrode allows for observing the OER at a more favorable potential: About $50 \mathrm{mV}$ (i.e., a cathodic, less positive, shift of the potential at which the oxygen evolution is observed).
\end{abstract}

Keywords: spin dependent electrochemistry; water splitting; nickel; chirality; OER

\section{Introduction}

Nowadays, the energy problem is a crucial challenge to be faced. Hydrogen could be a decisive way out of it, because hydrogen is considered as the ultimate fuel for several reasons: (i) It has the highest specific enthalpy of combustion of any chemical fuel, (ii) it has no carbon or $\mathrm{CO}_{2}$ waste, and (iii) water is the combustion's final product. In the present situation, $80 \%$ of the sources of energy production are traditional ones (such as oil, coal, and natural gas). The perspective related to pollution issues and future shortage of oil and coal leads to a search for a different type of fuel. The latter should effectively be coupled with alternative energy sources: Photovoltaic, hydroelectric, wind turbine, geothermal, and tidal power. All these energy sources produce electricity as the final form of energy. On the whole, energy obtained via "renewable energy" sources in 2015 represented the $16.7 \%$ of the installed power in the U.S.A. for the $13.8 \%$ of the total world-wide electricity generation (including the hydrogen production that reached $10^{10} \mathrm{~kg}$ in 2015 in U.S.A) [1-4]. With a global demand ranging between 70 and 80 million tons of hydrogen per year [5]. In addition, the worldwide percentage of energy produced by renewable energy is higher than in the U.S.A., reaching the $24 \%$ of the total [5], with the $58 \%$ purchased from hydroelectric source. Within this picture, hydrogen role is growing in importance as it can be used as energy vector and/or fuel mixed with the fossil ones [6-8]. Concerning hydrogen, one of the hardest issues to be solved is its efficient storage, which has been the subject of extensive research and multiple solutions are currently viable. From classical liquid storage and high-pressure containers to "Metal hybrids" an "Metal hydride" compounds [9,10]. The hydrogen production via electrochemical 
dissociation of water is commonly addressed as water splitting (WS) [11-16]. Moreover, an appealing positive feature of the hydrogen production obtained via water splitting is its potential use "in-situ" linked to solar energy photovoltaic electric generation in low-cost organic cells [17-19]. The efficiency enhancement of water splitting can be achieved by taking advantage of spin filtering of the electron during the reduction process. The control, production, and measurement of spin polarization currents, within an electrochemical system, are studied in the research area of spin dependent electrochemistry (SDE) [20], in which the opportunity to gain further physical insight on the influence and the role of spin in the charge transport is revealed. Chiral organic compound have been discovered performing in a special kind of SDE called Chiral Induced Spin Selectivity (CISS) [21]. When an electron current passes through a chiral molecule, a spin filter effect takes place resulting in an imbalance between the alpha and beta spin of the electrons. This phenomenon has many implications in spintronics as well as in water splitting. The positive effect in WS due to the spin-filter effect has already been demonstrated for electrodes coated with chiral molecules [11,12,22-24]. This because "ideal" spin filtering would involve production of $\mathrm{OH}^{*}$ radicals only of alpha (or only of beta) spin, hindering the production of $\mathrm{H}_{2} \mathrm{O}_{2}$ (hydrogen peroxide), because two reacting $\mathrm{OH}^{*}$ radicals would yield hydrogen peroxide in the triplet state (which is $1 \mathrm{eV}$ higher in energy than the singlet electronic state). The latter is a highly reactive and corrosive compound, and it can be considered a side reaction's undesirable product of the $\mathrm{OH}^{-}$oxidation. The novelty of this work here consists in exploiting the CISS effect using chiral compounds in bulk solution, rather than adsorbed on the electrode surface (i.e., a bulk rather than an interfacial effect).

Indeed, it is known that the presence in bulk solution of chiral compounds is able to "induce" an enantio-selective or generate local spatial chirality effects: See for instance results obtained in chiral ionic liquids and enantio-recognition effects in achiral ionic liquids, this latter induced by the presence of suitable bulk chiral compounds (even in a low concentration) [25]. In principle, this allows an efficient production of hydrogen through the water splitting, but using a simpler and cheaper system (i) in terms of manufactory costs, being based only on preparing a bulk solution, and (ii) natural chiral compounds, tartaric acid in this specific case, are rather cheap when compared to metallic nanoparticles obtained by both expensive and environmentally-dangerous (for example the cadmium based nanoparticles [11,26]). The water-splitting process is studied as a function of different chiral additives/catalyzers on both a stainless steel and nickel electrodes, the latter deposited directly on a magnetic surface, to evaluate the best candidate for an efficient spin filtering reducing the production $\mathrm{H}_{2} \mathrm{O}_{2}$. In the case of the Ni-on-the-magnet electrode, the ferromagnetic material acts like a spin-injector as a function of the substrate magnetic field; while in the case of the steel electrode, the possible spin filtering is achieved only from the bulk solution chiral environment. The differences between these two different solutions are investigated.

The overall water splitting reaction is, in principle, a simple redox reaction:

$$
2 \mathrm{H}_{2} \mathrm{O} \rightarrow 2 \mathrm{H}_{2}+\mathrm{O}_{2} \quad \Delta \mathrm{E}=1.23 \mathrm{~V} \text { vs. RHE. }
$$

In fact, the reaction is much more complex, in particular for the water oxidation at the anode. Here, in fact, the oxygen evolution reaction (OER) occurs via a multi-step process, which involves a rather complex reaction mechanism featuring the transfer of 4 electrons [27].

The mechanism depends on a number of chemical as well as physical parameters, and in particular on the solution $\mathrm{pH}$. In the following Equations (2)-(5), the overall half-cell reactions are reported:

Alkaline solution:

$$
\begin{array}{ll}
4 \mathrm{OH}^{-} \rightarrow \mathrm{O}_{2}+2 \mathrm{H}_{2} \mathrm{O}+4 e^{-} & E_{a}^{0}=0.401 \mathrm{~V} \text { vs. NHE } \\
4 \mathrm{H}_{2} \mathrm{O}+4 e^{-} \rightarrow 2 \mathrm{H}_{2}+4 \mathrm{OH}^{-} & E_{c}^{0}=-0.828 \mathrm{~V} \text { vs. NHE }
\end{array}
$$

Acid solution: 


$$
\begin{gathered}
2 \mathrm{H}_{2} \mathrm{O} \rightarrow \mathrm{O}_{2}+4 \mathrm{H}^{+}+4 e^{-} \quad E_{a}^{0}=1.229 \mathrm{~V} \text { vs. NHE } \\
4 \mathrm{H}^{+}+4 e^{-} \rightarrow \mathrm{H}_{2} \quad E_{c}^{0}=0.00 \mathrm{~V} \text { vs. NHE }
\end{gathered}
$$

In principle, the potentials associated to reactions (2) and (4) are the thermodynamic values relevant to the OER, but beyond the thermodynamic potential it is necessary to apply an overpotential to observe the gas evolution. The key to improve the process efficiency is to minimize the overpotential [11-13]. The following sequence of elementary reaction steps represents the step-by-step overall reaction that occurs at the anode in an acid solution (where $M$ represent the anode metallic conductive substrate) [27-30].

$$
\begin{gathered}
M+\mathrm{H}_{2} \mathrm{O}_{(\text {bulk })} \rightarrow(\mathrm{M}) \mathrm{OH}_{(a d s)}+H_{(\text {sol })}^{+}+e^{-} \quad \Delta \mathrm{G}_{1} \\
(\mathrm{M}) \mathrm{OH}_{(\text {ads })} \rightarrow(\mathrm{M}) \mathrm{O}_{(\text {ads })}+H_{(\text {sol })}^{+}+e^{-} \quad \Delta \mathrm{G}_{2} \\
(\mathrm{M}) \mathrm{O}_{(a d s)}+\mathrm{H}_{2} \mathrm{O}_{(\text {bulk })} \rightarrow(\mathrm{M}) \mathrm{OOH}_{(a d s)}+H_{(s o l)}^{+}+e^{-} \quad \Delta \mathrm{G}_{3} \\
(\mathrm{M}) \mathrm{OOH}_{(a d s)} \rightarrow \mathrm{M}+\mathrm{O}_{2(\text { gas })}+H_{(\text {sol })}^{+}+e^{-} \quad \Delta \mathrm{G}_{4}
\end{gathered}
$$

$\Delta G_{i}$ is the Gibb's free energy of each elementary steps. As reported in literature [28,29], $\Delta G_{O E R}$ is the max of the four $\Delta G_{i}$ values, namely $\Delta G_{3} . \Delta G_{i}$ can be calculated with the formula $\Delta G^{0}=-n F E$ if all elementary steps are known and so the $\Delta E^{0}$ of the redox couple involved [31-33]. Those values are useful in compiling the Latimer diagram of the reaction, a compact diagram of each step involved in the redox chain, reported in Scheme 1, where numbers in the blue arrows represent the $\Delta E^{0}$ of the reactions from (6) to (9). The $\Delta E^{0}$ of the total reaction is the results of the equation $\frac{\sum_{1}^{4} n_{i} \Delta E_{i}^{0}}{\sum_{1}^{4} n_{i}}$ where $n_{i}$ represent the number of electrons exchanged during each step.

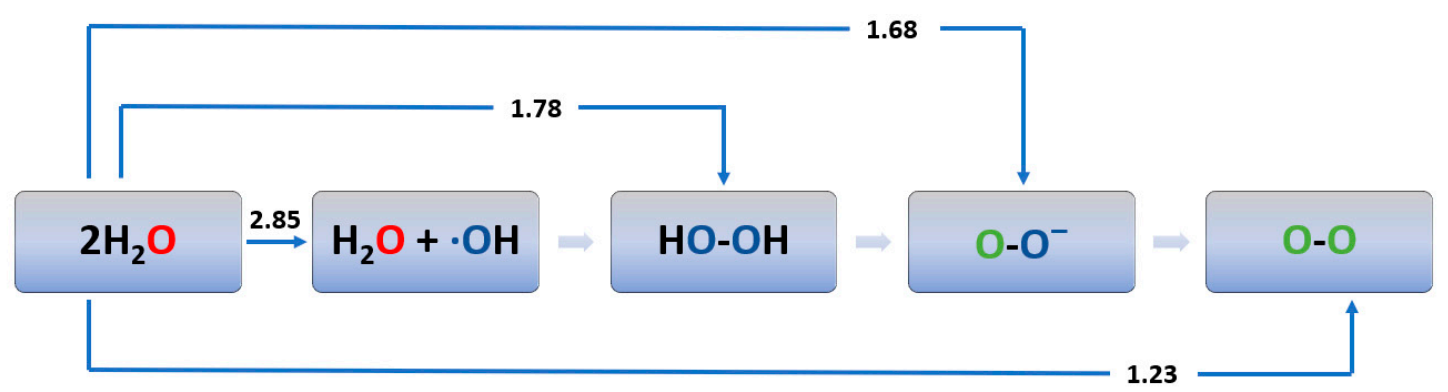

Scheme 1. Water electrolysis: Latimer reaction mechanism.

The energy for the reaction can be provided by different sources, e.g., with the use of light, often coupled with catalytic substrate, like $\mathrm{TiO}_{2}$ [34-36]. Remarkably, the final product at the anode, i.e., oxygen, is produced in its triplet state, which is the most stable molecular oxygen species. Here spin dependent electrochemistry can play a role. On the whole, the experimental electrochemical outcome allows to discuss the role played on the OER efficiency by the spin filtering effect, in relation to the chirality of compounds present in solution.

\section{Results and Discussion}

\subsection{Steel AISI $316 L$}

\subsubsection{L-(+)-Tartaric Acid}

Figure 1 shows cyclic voltammetry curves, obtained as a function of different concentrations of bulk L-(+)-tartaric acid, on the stainless steel working electrode. In both the forward and backward curves, the current is nearly negligible in the 0.0 to $0.6 \mathrm{~V}$ range. In the case of the base electrolyte solution (blue curve, Figure 1), at potential values larger than $0.6 \mathrm{~V}$ the current starts to increase almost 
linearly until reaching a final $2.5 \mathrm{~mA}$ value at $0.8 \mathrm{~V}$. Tartaric acid $0.5 \mathrm{mM}$ solution (green curve, Figure 1 ) shows a lower current, $2.4 \mathrm{~mA}$, at $0.8 \mathrm{~V}$. Tartaric acid $5 \mathrm{mM}$ solution (red curve, Figure 1) shows an initial higher current but at the potential where the OER occurs (around $0.8 \mathrm{~V}$ ) the current is lower when compared with the previous ones. Tartaric acid $25 \mathrm{mM}$ solution (black curve, Figure 1) shows the lowest current, $1.2 \mathrm{~mA}$, at $0.8 \mathrm{~V}$. The current appears to be correlated to the concentration of the chiral compound with an inverse proportionality. The inset of Figure 1 presents a more detailed CV, in the 0.5 to $0.75 \mathrm{~V}$ potential range. The inset shows a small but neat difference between the forward and backward scans. The current for the $\mathrm{KOH}$ base electrolyte solution is always higher than the one measured in presence of tartaric acid.

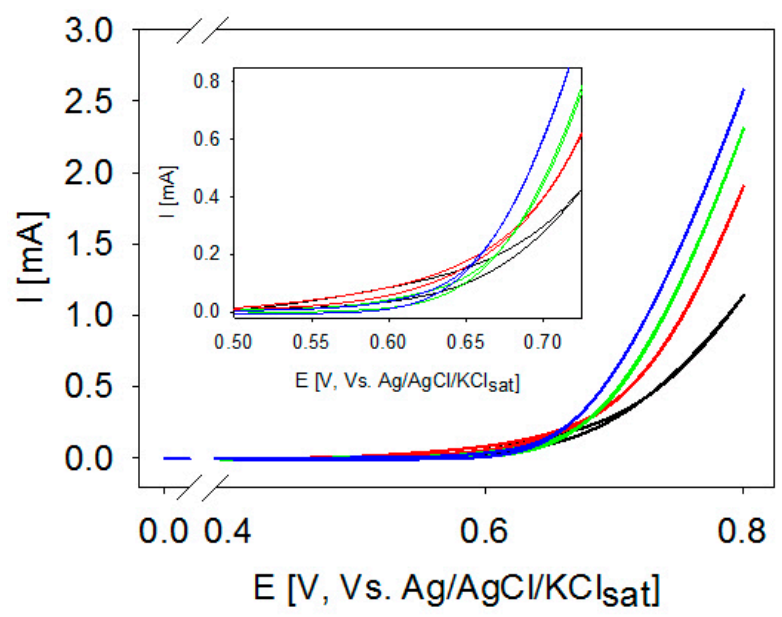

Figure 1. Cyclic voltammetry curves recorded on a steel AISI $316 \mathrm{~L}$ working electrode (WE). $50 \mathrm{mV} / \mathrm{s}$ potential scan rate, $\mathrm{Pt}$ sheet as counter $(\mathrm{CE})$ and $\mathrm{Ag} / \mathrm{AgCl} / \mathrm{KCl}_{\text {sat }}$ as $\mathrm{RE}$. $\mathrm{KOH} 0.1 \mathrm{M}$ aqueous solution is the base electrolyte. L-(+)-tartaric acid concentration: (blue) $0 \mathrm{mM}$, (green) $0.5 \mathrm{mM}$, (red) $5 \mathrm{mM}$, (black) $25 \mathrm{mM}$. The inset shows the CV detail in the 0.5 and $0.75 \mathrm{~V}$ potential range.

\subsubsection{L-(-)-Aspartic Acid}

Figure 2 shows CVs in solutions with different concentrations of L-(-)-aspartic acid. Qualitatively, CVs pattern is quite similar to that shown in Figure 1. Quantitatively, all the tartaric acid solutions at different concentration feature a lower current with respect to that of the base electrolyte. Note that, no peaks are evident in the backward scan, indicating that any reaction (OER) occurring during the forward scan (oxidation regime) is irreversible.

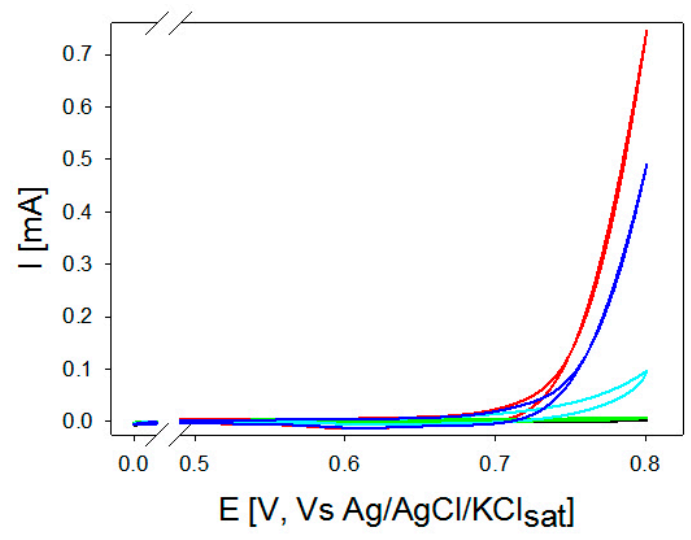

Figure 2. Cyclic voltammetry curves recorded on a steel AISI 316L WE. $50 \mathrm{mV} / \mathrm{s}$ potential scan rate, $\mathrm{Pt}$ sheet as $\mathrm{CE}$ and $\mathrm{Ag} / \mathrm{AgCl} / \mathrm{KCl}_{\text {sat }}$ as $\mathrm{RE}$. $\mathrm{KOH} 0.1 \mathrm{M}$ aqueous solution is the base electrolyte. L-(-)-aspartic acid concentration: (red) $0 \mathrm{mM}$, (blue) $1 \mathrm{mM}$, (light blue) $10 \mathrm{mM}$, (green) $50 \mathrm{mM}$, (black) $100 \mathrm{mM}$. 
CVs recorded by using a stainless steel anode, the L-(+)-tartaric acid and L-(-)-aspartic acid exert a blocking activity on the electrode. The anodic current is found to decrease as the concentration of the acid is increased (compare CVs shown in Figures 1 and 2). Probably this effect is due to simple coulombic attraction between the anode (charged positively) and the relevant acid anion, which can be adsorbed on the surface eventually leading to a decrease in the overall current.

\subsubsection{D-(+)-Glucose}

Figure 3 shows CVs as function of the concentration of D-(+)-glucose. A systematic variation in the current as a function of the D-(+)-glucose concentration is noted. The maximum efficiency, obtained comparing the current response at fixed potentials, is found for the $10 \mathrm{mM} \mathrm{D}-(+)$-glucose concentration (green curve, Figure 3). The $\mathrm{KOH}$ base electrolyte solution is characterized by the lowest current values (red curve, Figure 3).

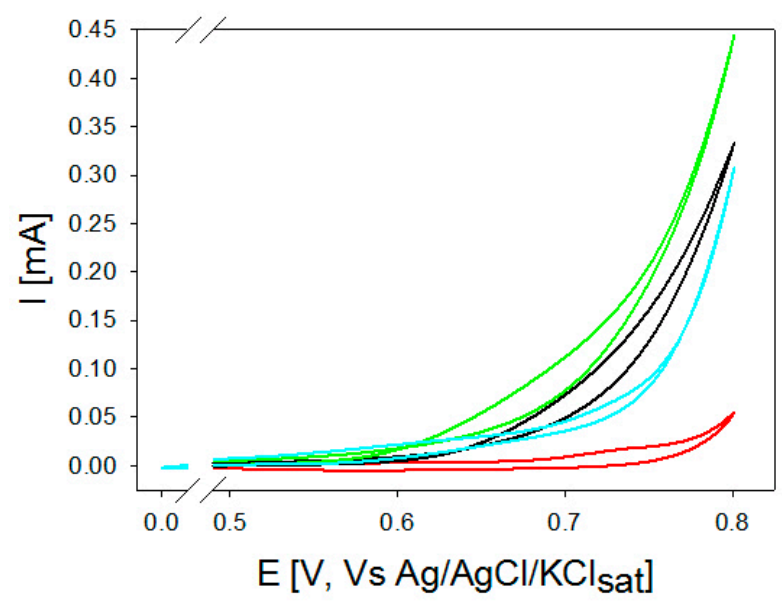

Figure 3. Cyclic voltammetry curves recorded on a steel AISI 316L WE. $50 \mathrm{mV} / \mathrm{s}$ potential scan rate, $\mathrm{Pt}$ sheet as $\mathrm{CE}$ and $\mathrm{Ag} / \mathrm{AgCl} / \mathrm{KCl}_{\text {sat }}$ as $\mathrm{RE}$. $\mathrm{KOH} 0.1 \mathrm{M}$ aqueous solution is the base electrolyte. D-(+)-glucose concentration: (red) $0 \mathrm{mM}$, (light blue) $1 \mathrm{mM}$, (green) $10 \mathrm{mM}$, (black) $100 \mathrm{mM}$.

A complex electrochemical behavior is found when the $\mathrm{D}-(+)$-glucose is present in the solution, Figure 3. The current is always found to be larger than that of the base electrolyte, and in terms of efficiency the current increases as a function of the concentration until $10 \mathrm{mM}$, then starts to decrease for larger concentrations (compare black line, $100 \mathrm{mM}$, Figure 3).

\subsection{Nickel Electrodeposited on Magnet}

\section{D-(+)-Glucose}

Figure 4 shows the cyclic voltammetry of Ni electrodeposited on the north surface of a permanent magnet used as working electrode in two different solutions: $\mathrm{D}-(+)$-glucose $0.1 \mathrm{M}$ in base electrolyte $(\mathrm{KOH} 0.1 \mathrm{M})$ and bare base electrolyte. The experimental set-up is the one with the Teflon cell described in Section 3 (3. Experimental). Note that values in Figures 4 and 5 are normalized to point out the differences between the current in the solution with the chiral compound and the one with only the support electrolyte $\mathrm{KOH}$. The value that has been used to normalize the data was the current associated to the oxidation of the Ni surface, otherwise the current peak, in the forward scan, in the base electrolyte curve: An opportune dividing coefficient is adopted in order to make that peak current value equal to 1. In the case of pure electrolyte $\mathrm{KOH}$ solution (red curve, Figure 4) the Ni peaks are evident, with the oxidation one happening at $0.55 \mathrm{~V}$ in the forward scan while during the backward scan the reduction peak splits in two smaller peaks, one at $0.39 \mathrm{~V}$ and the other at $0.46 \mathrm{~V}$. Otherwise, the curve describing the current in the solution containing the chiral compound is completely different, resulting more like the one found with the stainless steel electrode (Figure 3). In particular, the D-(+)-Glucose curve 
doesn't have the peaks of the Ni nor in forward nor in backward scan. The absence of peaks in the glucose's curve means that the redox process became irreversible if the glucose is added to the $\mathrm{KOH}$ solution. The anodic peak current in the solution containing the chiral compound results being $50 \%$ higher than the one measured with only the support electrolyte.

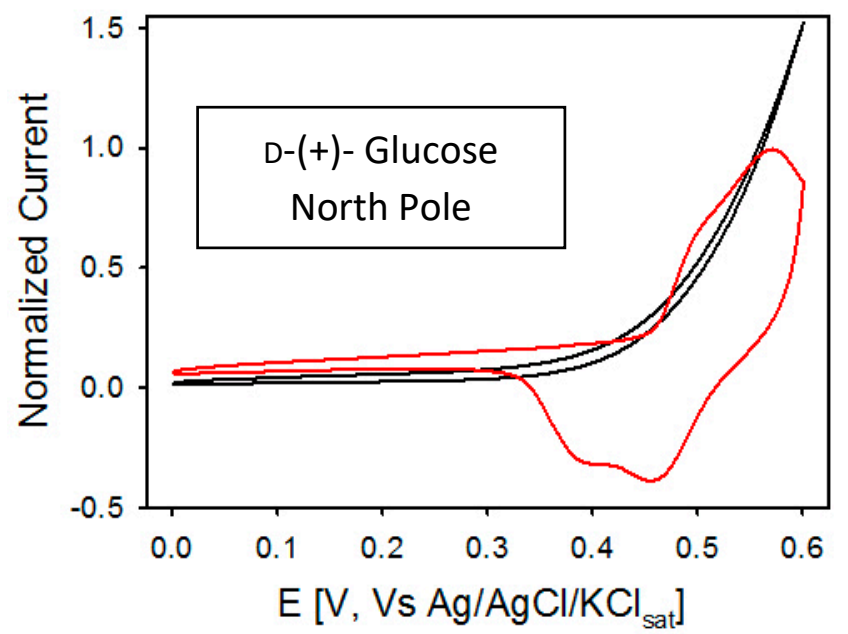

Figure 4. Normalized cyclic voltammetry curves recorded with electrodeposited Ni on the North pole of the magnet. Red curve: $\mathrm{KOH} \mathrm{0.1} \mathrm{M} \mathrm{aqueous} \mathrm{solution.} \mathrm{Black} \mathrm{curve:} 0.1 \mathrm{M}$ of $\mathrm{D}-(+)-\mathrm{Glucose}$ in $\mathrm{KOH}$ $0.1 \mathrm{M}$ aqueous solution. $50 \mathrm{mV} / \mathrm{s}$ potential scan rate, a $\mathrm{Pt}$ as $\mathrm{CE}, \mathrm{Ag} / \mathrm{AgCl} / \mathrm{KCl}_{\text {sat }}$ as $\mathrm{RE}$.

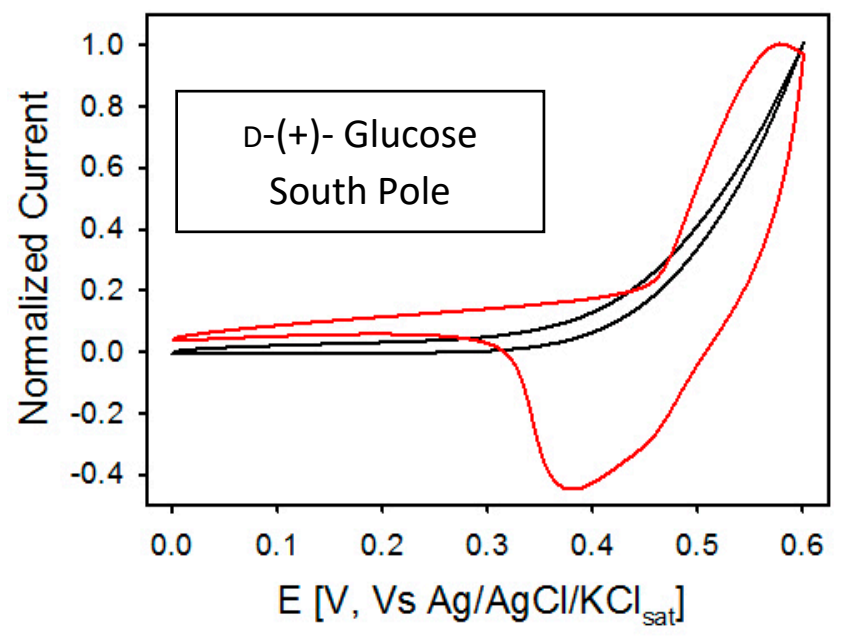

Figure 5. Normalized cyclic voltammetry curves recorded with electrodeposited $\mathrm{Ni}$ on the south pole of the magnet. Red curve: $\mathrm{KOH} 0.1 \mathrm{M}$ aqueous solution. Black curve: $0.1 \mathrm{M}$ of $\mathrm{D}-(+)-\mathrm{Glucose}$ in $\mathrm{KOH}$ $0.1 \mathrm{M}$ aqueous solution. $50 \mathrm{mV} / \mathrm{s}$ potential scan rate, $\mathrm{Pt}$ as $\mathrm{CE}, \mathrm{Ag} / \mathrm{AgCl} / \mathrm{KCl}$ as reference electrodes (RE).

Figure 5 shows the cyclic voltammetry measured on Ni electrodeposited on the south pole of the permanent magnet used as working electrode; those experiments were carried out with the same solutions of Figure 4, in the same operative conditions. Also in this case D-(+)-Glucose CV curve does not show the characteristic peaks associated to the oxidation and the reduction of the Ni. For what concerns the support electrolyte, the graph shows one peak at $0.55 \mathrm{~V}$ in oxidation and one peak and a shoulder in reduction at $0.37 \mathrm{~V}$ and $0.45 \mathrm{~V}$ respectively, coherent to what has been already seen in Figure 4. Also in Figure 5 the data relevant to the current, ordinate axis, have been normalized using the value of the current associated to the oxidation peak of the support electrolyte, so that peak would result having value equals to 1 on the normalized axis. In comparison with Figure 4 , the current of the solution containing the chiral compound is lower in the south pole, resulting having the maximum current in oxidation almost equal to the one measured with the support electrolyte. 
Figure 6 shows the comparison between CVs collected with a Ni electrode on top of north and south magnet polarities, recorded in a wider potential range. Remarkably, at $1.2 \mathrm{~V}$ it is present a peak for both the curves and the north pole peak current of the oxidation process is larger than the south pole corresponding value.

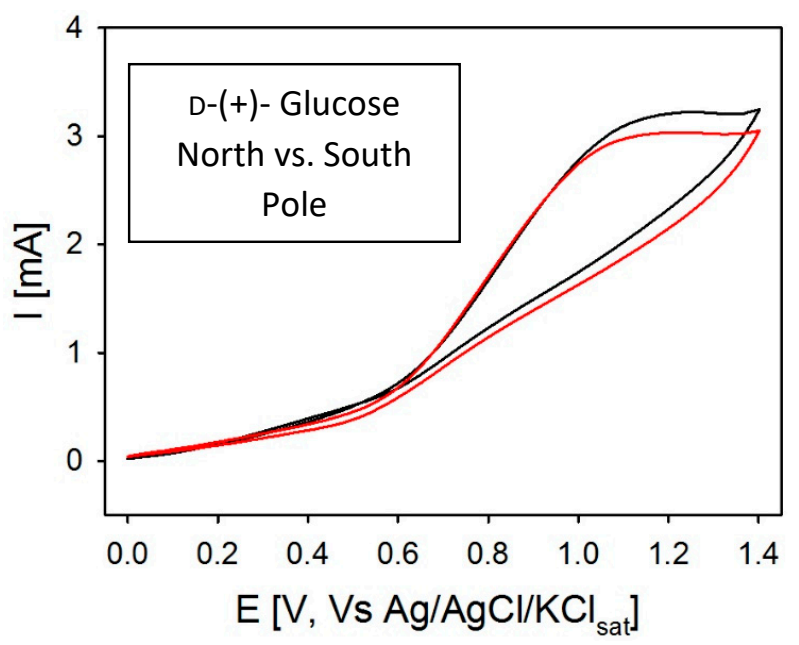

Figure 6. Comparison between cyclic voltammetry curves recorded with electrodeposited Ni on both

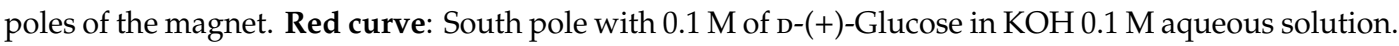

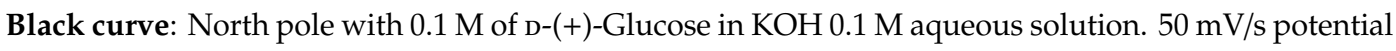
scan rate, $\mathrm{Pt}$ as $\mathrm{CE}, \mathrm{Ag} / \mathrm{AgCl} / \mathrm{KCl}$ as $\mathrm{RE}$.

\subsection{Step and Sweeps}

For a more accurate visual detection of the actual OER starting potential, "step and sweeps" technique measurements were performed. In fact, differently from the previous CVs, these experiments feature incremental values of potential which is maintained constant for a chosen amount of time. These measurements are reported in Figures 7 and 8, showing the anodic current recorded as a function of time during the potential ramp for two different electrodes.

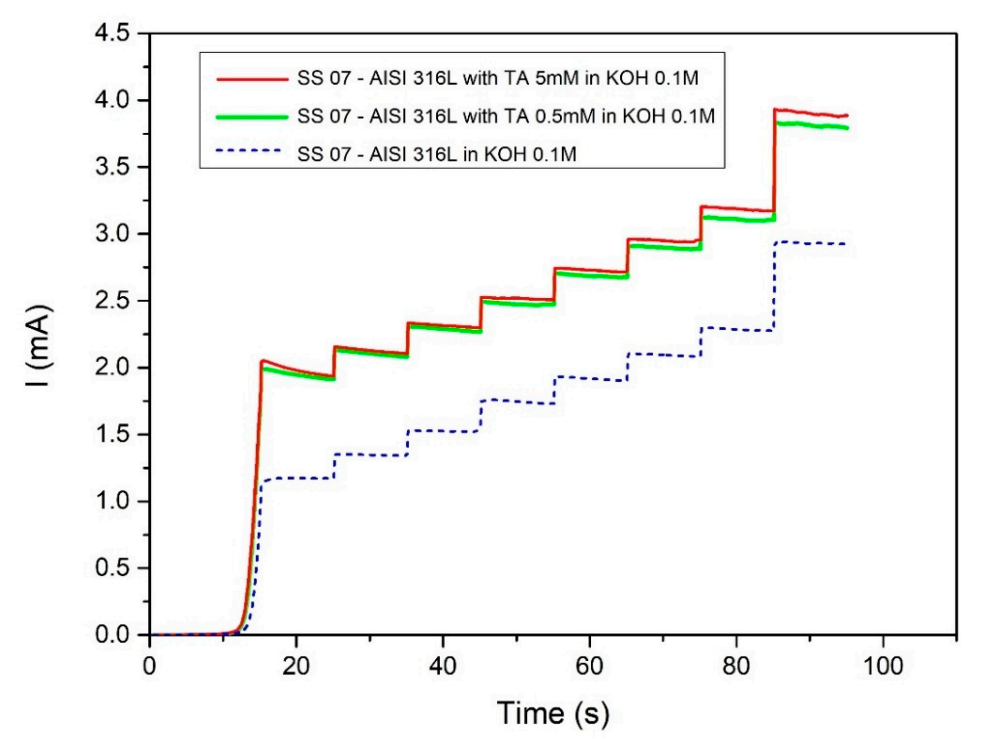

Figure 7. Step and sweeps curves recorded on a steel AISI 316L WE, Pt sheet as CE and $\mathrm{Ag} / \mathrm{AgCl} / \mathrm{KCl}_{\text {sat }}$ as $\mathrm{RE}$. $\mathrm{KOH} 0.1 \mathrm{M}$ aqueous solution is the base electrolyte. A potential ramp from 0 to $0.75 \mathrm{~V}$ at a $50 \mathrm{mV} / \mathrm{s}$ was applied, followed by eight $+0.01 \mathrm{~V}$ potential steps, up to $0.83 \mathrm{~V}$. The potential was maintained constant for $10 \mathrm{~s}$ between each step. L-(+)-tartaric acid concentration: (blue dash) $0 \mathrm{mM}$, (green) $0.5 \mathrm{mM}$, (red) $5 \mathrm{mM}$. 


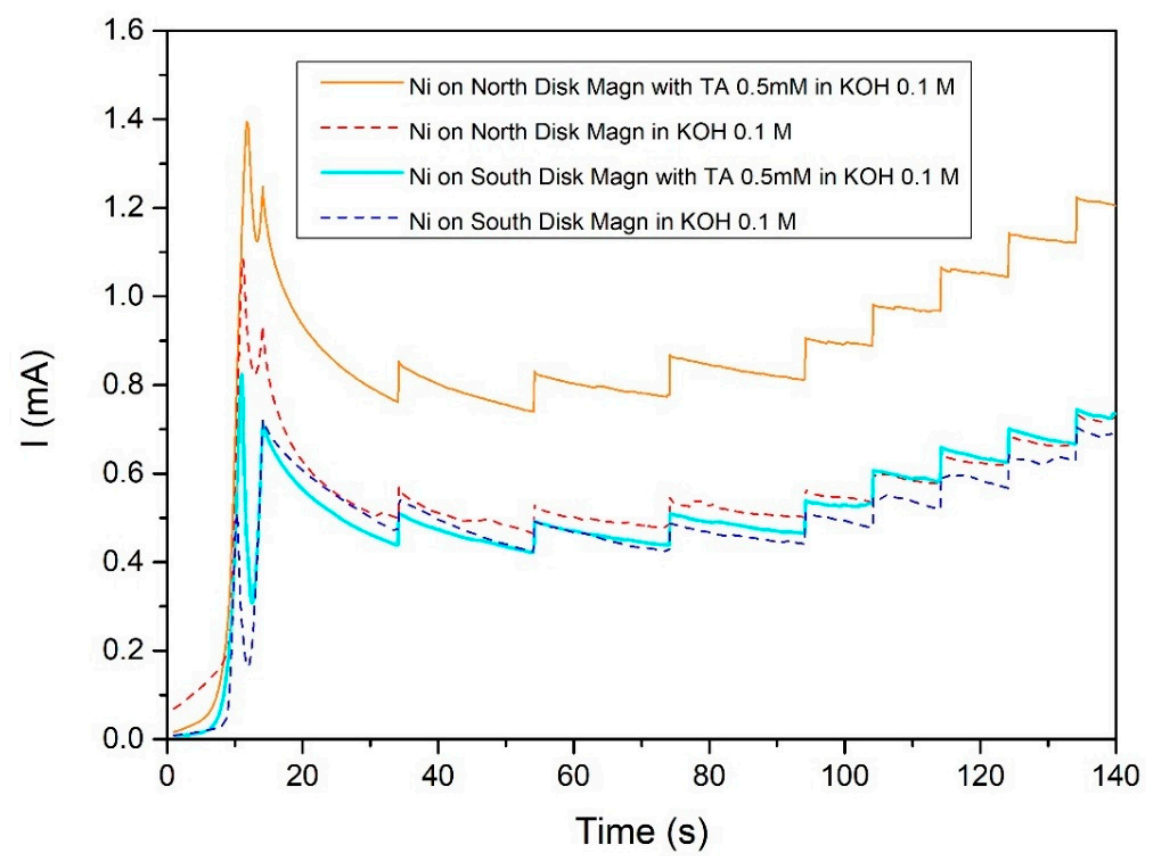

Figure 8. Step and sweeps curves recorded on a Ni deposited on magnet working electrode, a Pt sheet is the $\mathrm{CE}, \mathrm{Ag} / \mathrm{AgCl} / \mathrm{KCl}$ is the $\mathrm{RE} . \mathrm{KOH} 0.1 \mathrm{M}$ aqueous solution the base electrolyte. First a potential ramp from 0 to $0.70 \mathrm{~V}$ at a $50 \mathrm{mV} / \mathrm{s}$ was applied, followed by eight $+0.01 \mathrm{~V}$ potential steps, up to $0.78 \mathrm{~V}$. The potential was maintained constant for $15 \mathrm{~s}$ between each step. $\mathrm{L}-(+)$-tartaric acid concentration: (blue dash) South mag orientation $0 \mathrm{mM}$, (red dash) South mag orientation $0 \mathrm{mM}$, (light blue) South mag orientation $0.5 \mathrm{mM}$, (orange) North mag orientation $0.5 \mathrm{mM}$.

\subsubsection{Step and Sweeps on AISI $316 \mathrm{~L}$}

Step and sweeps were performed using the AISI $316 \mathrm{~L}$ steel sheet as working electrode, with the $\mathrm{L}-(+)$-tartaric acid present in bulk solution. The applied potential program as a function of time features a first potential ramp from 0 to $0.75 \mathrm{~V}$ at a $50 \mathrm{mVs}^{-1}$ scan rate, followed by eight $+0.01 \mathrm{~V}$ potential steps, up to $0.83 \mathrm{~V}$. The potential was maintained constant for $10 \mathrm{~s}$ before the next step. Tartaric acid concentration 0.5 and $5 \mathrm{mM}$ in bulk solution was used. A rather large increase in the current was found, which should reflect a more efficient way to produce oxygen. Indeed, visual observation of the anode shows that the oxygen evolution occurs at more negative (smaller) potentials, anticipating the OER between 20 to $30 \mathrm{mV}$ with respect to the pure $\mathrm{KOH}$ base electrolyte solution (the relevant table (Table S1) is present in the Supplementary Materials).

\subsubsection{Step and Sweeps Ni-on-magnet}

Stepped potential sweeps experiments were recorded also exploiting a ferromagnetic electrode in tight contact with a magnet: The Ni electrodeposited on magnet (Ni-on-magnet) electrode. This to possibly maximize the spin-injection efficiency. Figure 8 shows the anodic current recorded as a function of time: Measurements have been carried out with L-(+)-tartaric acid present in bulk solution, as well as with the pure $0.1 \mathrm{M} \mathrm{KOH}$ base electrolyte for reference purposes. The applied potential program as a function of time features a first potential ramp from 0 to $0.70 \mathrm{~V}$ at a $50 \mathrm{mVs}^{-1}$ scan rate, followed by $+0.01 \mathrm{~V}$ potential steps, maintained constant for $15 \mathrm{~s}$. The tartaric acid concentration is $0.5 \mathrm{mM}$ in bulk solution. Results show two different situations depending on the orientation of the substrate magnet. In fact, when the Nickel sheet lays on the south pole of the magnet, the oxidation current results slightly higher for the TA solution than the $\mathrm{KOH}$ alone; moreover, a huge current increase can be observed between the chiral solution and the basic one when the North pole of the magnet is used. A significant increase in the current is found, which reflects a more efficient way to produce oxygen. Indeed, for both the North and the South magnet pole visual observation of the 
anode shows that the oxygen evolution occurs at more negative (smaller) potentials, anticipating the OER between 30 to $50 \mathrm{mV}$ with respect to the pure $\mathrm{KOH}$ base electrolyte solution (Table S1 in the Supplementary Materials).

In the case of the ferromagnetic Ni surface, deposited on a magnet acting as substrate, is used as the anode. In the case of the $\mathrm{L}-(+)$-tartaric acid, Figure 8, the current recorded in response to potential step and sweeps in the presence of the bulk chiral compound is always larger than that of the base electrolyte. In this peculiar case, the effect of the presence of the chiral compound in bulk solution has been investigated by comparing the peak current values as a function of the magnet orientation (North vs. South), showing significant differences in the values of the current obtained at a fixed potential. Such an analysis is a crucial issue in unravelling the role of the spin. Moreover, to obtain a complete picture, the electrochemical results can be compared for the two enantiomers. Altogether four different situations are to be quantitatively compared: (1) L-(+)-tartaric acid North (2) L-(+)-tartaric acid south (3) D-(-)-tartaric acid north (4) D-(-)-tartaric acid south. Tables S2-S5 report, in the most synthetic way, the current results obtained performing CVs in all four cases. Moreover, Table S6 and Table S7 aim to present in a clear and simple way, as much as possible, the catalytic effect observed in the different combination of enantiomers and the magnet pole. In particular, the sign found in column titled "sgn (J $\mathrm{J}_{\text {ratio }}$ North - J Jatio South)" (Table S6 and Table S7) exhibit what is the most efficient combination. Remarkably, the L-(+)-tartaric acid North is more effective than L-(+)-tartaric acid South in a consistent way, while the $\mathrm{D}-(-)$-tartaric acid south combination is found more effective than the $\mathrm{D}-(-)$-tartaric acid North (coherently with the results of the step and sweeps previously presented in Section 2.3.2). In the case of the glucose, only the $\mathrm{D}-(+)$-glucose enantiomer was examined and it is found that the current for the $\mathrm{D}-(+)$-glucose north combination is larger than the $\mathrm{D}-(+)$-glucose south one, Figures 4 and 5. Please note that due to fluctuations in the base electrolyte CVs, in Figures 4 and 5 normalized data are presented. Tables S8 and S9 report the percentage of spin polarization of currents in the experiments made on the different Ni surface deposited on poles' magnet. Those values are calculated with the Formula (10).

$$
\frac{\left(\frac{J_{(\text {Tart })}}{J_{(\text {KOH })}}\right)_{(\text {North })}-\left(\frac{J_{(\text {Tart })}}{J_{(\text {KOH })}}\right)_{(\text {South })}}{\left(\frac{J_{(\text {Tart })}}{J_{(\text {KOH })}}\right)_{(\text {North })}+\left(\frac{J_{(\text {(art })}}{J_{(\text {KOH })}}\right)_{(\text {South })}}=S P \%
$$

\section{Experimental}

\subsection{Materials}

L-(+)-tartaric acid (the natural available enantiomer), L-(-)-aspartic acid, D-(+)-glucose were purchased from Sigma Aldrich and used without further purifications. Only a single enantiomer of each compound is used in the experiments. In fact, if a variation is not applied to the system in order to break its symmetry, measures with opposite sign enantiomers would give the same outcome results. The nickel electrodeposition was carried out using a classical Watt's Bath (WB), whose composition is: $150 \mathrm{~g} / \mathrm{L}$ of nickel sulphate, nickel chloride, $37 \mathrm{~g} / \mathrm{L}$ boric acid $\mathrm{H}_{3} \mathrm{BO}_{3}, \mathrm{pH}=5$.

\subsection{Methods}

Thus, experiments of electrochemical water splitting were carried out using two different anodes: (i) A stainless steel AISI 316 L electrode, and (ii) Ni electrodeposited directly on the North (or South) pole surface of a permanent magnet (Ni-on-the-magnet electrode). Cyclic voltammetry results are presented focusing on the response of the anodic OER. In the case of the AISI 316L steel, results were collected using, $\mathrm{L}-(+)$-tartaric acid, $\mathrm{D}-(-)$-aspartic acid, and $\mathrm{D}-(+)$-glucose. In the case of $\mathrm{Ni}$-on-the-magnet electrode, $\mathrm{CV}$ measurements were still performed with bulk concentrations of D-(+)-glucose, $\mathrm{L}-(+)$-tartaric acid, and D-(-)-tartaric acid, and particular focus was also payed to potential sweeps experiments in presence of $\mathrm{L}-(+)$-tartaric acid. 


\subsection{Electrochemical System}

Cyclic voltammetry (CV) measurements were performed using both Autolab PGSTAT 128N and $\mathrm{CHI} 660 \mathrm{~A}$ potentiostats, employing a typical three-electrode electrochemical cell arrangement concerning the measurements involving the stainless-steel working electrode. A different arrangement was adopted in the case of the Ni electrodeposited on the magnet: A Teflon cell, featuring a hole $(0.8 \mathrm{~cm}$ diameter) in the bottom, was used in a vertical configuration where the Ni-on-the-magnet working electrode was tightened from below, a Teflon ring was used to ensure no solution leakage from the cell. An image is shown in the Supplementary Materials Figure S1. Thus, Steel AISI 316L or the Ni-on-the-magnet surfaces were used as working electrodes (WE), while a Pt wire and a silver, silver chloride, $\mathrm{KCl}$ saturated solution $\left(\mathrm{Ag} / \mathrm{AgCl} / \mathrm{KCl}_{\text {sat }}\right)$ electrodes were the counter (CE) and reference electrodes (RE), respectively. In order to check the quality of the nickel surface obtained via electrodeposition on the magnet, control experiments were carried out using glassy carbon, $\mathrm{Pt}$ and evaporated gold as working electrodes [37]. A $\mathrm{KOH} 0.1 \mathrm{M}$ aqueous solution is used as base electrolyte in all reported electrochemical measurements.

\section{Conclusions}

This work explored the influence of chiral compounds in bulk solution on the hydrogen production process pursued via water electrolysis, often addressed as "water splitting". To this end two different electrode materials (steel and $\mathrm{Ni}$ ) and three organic chiral compounds (tartaric acid, aspartic acid, and glucose) were selected. Assessment of the catalytic activity of the different combinations of organic compound and electrode material was performed by measuring CVs under controlled conditions. The $\mathrm{KOH} 0.1 \mathrm{M}$ aqueous solution base electrolyte was selected as the experimental reference situation to evaluate the catalytic effect on the water splitting process. Chiral compounds have been selected because they are known to enhance the OER efficiency due to spin effects [11-16]. The results are encouraging both on steel and on $\mathrm{Ni}$ as well. The $\mathrm{L}-(+)$-tartaric acid yields a moderate potential shifting effect ( $50 \mathrm{mV}$ in the most favorable case), just on the shoulder preceding the current ramp for the OER. On the contrary, the aspartic acid does not seem to exert any prominent effect. In the case of the Ni working electrode the effect of the magnetic field, to select "up" and "down" spin injection, was investigated. Here the most interesting results are obtained. The comparison of the oxidation current peak, essentially due to the oxygen evolution reaction, yields a final consistent picture. Where the $\mathrm{L}-(+)$-tartaric acid is found to enhance the evolution when the north-pole of the magnet is placed in direct contact with the $\mathrm{Ni}$ anode surface, the situation is reversed, i.e., larger efficiency for the D-(-)-tartaric acid coupled with the south magnetic field orientation. By and large, it appears that the results obtained using bulk chiral compounds yield a consistent spin filtering effect. On the whole, an average $4 \%$ spin polarization value is obtained (average obtained by the SP values of each measurement), a value which is definitively less than the $15 \%$ to $20 \%$ SP range obtained in the case of well-ordered adsorbed monolayers directly on top of the electrode surface. All in all, the results obtained especially on the $\mathrm{Ni}$ as a function of the magnet orientation, relate well with results previously presented in the literature. This gives further impulse to the scientific research in the field of spin effects in the OER process.

Supplementary Materials: The following are available online. Table S1: Step and Sweeps on AISI 316 L; Table S2 and Table S3: CVs of Ni-on-magnet (North pole and South pole) with L-(+)-tartaric acid; Table S4 and Table S5: CVs of Ni-on-magnet (North pole and South Pole) with D-(-)-tartaric acid; Table S6: CVs of Ni-on-magnet (North pole and South Pole) with L-(+)-tartaric acid and focus on the result of the sign function of the difference between North and South pole; Table S7: CVs of Ni-on-magnet (North pole and South Pole) with D-(-)-tartaric acid and focus on the result of the sign function of the difference between North and South pole; Table S8: values of spin polarization $(\mathrm{SP} \%)$ of the current in the measurements made with L-(+)-tartaric acid; Table S9: values of spin polarization (SP\%) of the current in the measurements made with D-(-)-tartaric acid.

Author Contributions: Data curation, A.S.; Formal analysis, M.B. and W.G.; Investigation, M.G.; Supervision, C.F.; Writing-original draft, C.F.; Writing-review and editing, M.I. All authors have read and agreed to the published version of the manuscript. 
Funding: Financial support for this research by University of Modena and Reggio Emilia (Department of Engineering 'Enzo Ferrari'), through "Photo-electrochemical water splitting" (FAR 2019) project. W.G. acknowledges financial support from PRIN ("Progetti di Ricerca di Rilevante Interesse Nazionale"): Novel Multilayered and Micro-Machined Electrode Nano-Architectures for Electrocatalytic Applications (Fuel Cells and Electrolyzers), grant 2017YH9MRK.

Conflicts of Interest: The authors declare no conflict of interest.

\section{References}

1. Beiter, P.; Tian, T. 2015 Renewable Energy Data Book; National Renewable Energy Lab (NREL): Golden, CO, USA, 2016.

2. Sinsel, S.R.; Riemke, R.L.; Hoffmann, V.H. Challenges and solution technologies for the integration of variable renewable energy sources-A review. Renew. Energy 2020, 145, 2271-2285. [CrossRef]

3. Global Energy Review 2019-Analysis. Available online: https://www.iea.org/reports/global-energy-review2019 (accessed on 20 August 2020).

4. BP Statistical Review of World Energy, 68th ed. 2019. Available online: www.bp.com (accessed on 29 August 2020).

5. IEA. The Future of Hydrogen. 2019. Available online: https://www.iea.org/publications/reports/ thefutureofhydrogen/ (accessed on 29 August 2020).

6. AlRafea, K.; Fowler, M.; Elkamel, A.; Hajimiragha, A. Integration of renewable energy sources into combined cycle power plants through electrolysis generated hydrogen in a new designed energy hub. Int. J. Hydrogen Energy 2016, 41, 16718-16728. [CrossRef]

7. Krajačić, G.; Martins, R.; Busuttil, A.; Duić, N.; da Graça Carvalho, M. Hydrogen as an energy vector in the islands' energy supply. Int. J. Hydrogen Energy 2008, 33, 1091-1103. [CrossRef]

8. Ntziachristos, L.; Kouridis, C.; Samaras, Z.; Pattas, K. A wind-power fuel-cell hybrid system study on the non-interconnected Aegean islands grid. Renew. Energy 2005, 30, 1471-1487. [CrossRef]

9. Züttel, A. Materials for hydrogen storage. Mater. Today 2003, 6, 24-33. [CrossRef]

10. Niaz, S.; Manzoor, T.; Pandith, A.H. Hydrogen storage: Materials, methods and perspectives. Renew. Sustain. Energy Rev. 2015, 50, 457-469. [CrossRef]

11. Mtangi, W.; Kiran, V.; Fontanesi, C.; Naaman, R. Role of the electron spin polarization in water splitting. J. Phys. Chem. Lett. 2015, 6, 4916-4922. [CrossRef]

12. Mtangi, W.; Tassinari, F.; Vankayala, K.; Vargas Jentzsch, A.; Adelizzi, B.; Palmans, A.R.A.; Fontanesi, C.; Meijer, E.W.; Naaman, R. Control of electrons' spin eliminates hydrogen peroxide formation during water splitting. J. Am. Chem. Soc. 2017, 139, 2794-2798. [CrossRef]

13. Fontanesi, C.; Naaman, R.; Mtangi, W. Water Splitting Method and System. WO/2016/056011, 14 April 2016.

14. Liang, X.; Liu, J.; Zeng, D.; Li, C.; Chen, S.; Li, H. Hydrogen generation promoted by photocatalytic oxidation of ascorbate and glucose at a cadmium sulfide electrode. Electrochim. Acta 2016, 198, 40-48. [CrossRef]

15. Garcés-Pineda, F.A.; Blasco-Ahicart, M.; Nieto-Castro, D.; López, N.; Galán-Mascarós, J.R. Direct magnetic enhancement of electrocatalytic water oxidation in alkaline media. Nat. Energy 2019, 4, 519-525. [CrossRef]

16. Haschke, S.; Pankin, D.; Petrov, Y.; Bochmann, S.; Manshina, A.; Bachmann, J. Design rules for oxygen evolution catalysis at porous iron oxide electrodes: A 1000-fold current density increase. ChemSusChem 2017, 10, 3644-3651. [CrossRef] [PubMed]

17. Morvillo, P.; Parenti, F.; Diana, R.; Fontanesi, C.; Mucci, A.; Tassinari, F.; Schenetti, L. A novel copolymer from benzodithiophene and alkylsulfanyl-bithiophene: Synthesis, characterization and application in polymer solar cells. Sol. Energy Mater. Sol. Cells 2012, 104, 45-52. [CrossRef]

18. Morvillo, P.; Diana, R.; Fontanesi, C.; Ricciardi, R.; Lanzi, M.; Mucci, A.; Tassinari, F.; Schenetti, L.; Minarini, C.; Parenti, F. Low band gap polymers for application in solar cells: Synthesis and characterization of thienothiophene-thiophene copolymers. Polym. Chem. 2013. [CrossRef]

19. Appleyard, S.J. Simple photovoltaic cells for exploring solar energy concepts. Phys. Educ. 2006, 41, 409. [CrossRef]

20. Mishra, D.; Markus, T.Z.; Naaman, R.; Kettner, M.; Göhler, B.; Zacharias, H.; Friedman, N.; Sheves, M.; Fontanesi, C. Spin-dependent electron transmission through bacteriorhodopsin embedded in purple membrane. Proc. Natl. Acad. Sci. USA 2013, 110, 14872-14876. [CrossRef]

21. Ray, K.; Ananthavel, S.P.; Waldeck, D.H.; Naaman, R. Asymmetric scattering of polarized electrons by organized organic films of chiral molecules. Science 1999, 283, 814-816. [CrossRef] [PubMed] 
22. Carmeli, I.; Kumar, K.S.; Heifler, O.; Carmeli, C.; Naaman, R. Spin selectivity in electron transfer in photosystem, I. Angew. Chem. Int. Ed. 2014, 53, 8953-8958. [CrossRef]

23. Naaman, R.; Waldeck, D.H. Chiral-induced spin selectivity effect. J. Phys. Chem. Lett. 2012, 3, $2178-2187$. [CrossRef]

24. Tassinari, F.; Mathew, S.P.; Fontanesi, C.; Schenetti, L.; Naaman, R. Electric-field-driven alignment of chiral conductive polymer thin films. Langmuir 2014, 30, 4838-4843. [CrossRef]

25. Rizzo, S.; Arnaboldi, S.; Mihali, V.; Cirilli, R.; Forni, A.; Gennaro, A.; Isse, A.A.; Pierini, M.; Mussini, P.R.; Sannicolò, F. “Inherently chiral” ionic-liquid media: Effective chiral electroanalysis on achiral electrodes. Angew. Chem. Int. Ed. 2017, 56, 2079-2082. [CrossRef]

26. Yuan, Y.-J.; Chen, D.; Yu, Z.-T.; Zou, Z.-G. Cadmium sulfide-based nanomaterials for photocatalytic hydrogen production. J. Mater. Chem. A 2018, 6, 11606-11630. [CrossRef]

27. Sala, X.; Maji, S.; Bofill, R.; García-Antón, J.; Escriche, L.; Llobet, A. Molecular water oxidation mechanisms followed by transition metals: State of the art. Acc. Chem. Res. 2014, 47, 504-516. [CrossRef] [PubMed]

28. Buxton, G.V.; Greenstock, C.L.; Helman, W.P.; Ross, A.B. Critical Review of rate constants for reactions of hydrated electrons, hydrogen atoms and hydroxyl radicals $\left(\cdot \mathrm{OH} / \cdot \mathrm{O}^{-}\right.$in Aqueous Solution. J. Phys. Chem. Ref. Data 1988, 17, 513-886. [CrossRef]

29. Dau, H.; Limberg, C.; Reier, T.; Risch, M.; Roggan, S.; Strasser, P. The mechanism of water oxidation: From electrolysis via homogeneous to biological catalysis. Chem. Cat. Chem. 2010, 2, 724-761. [CrossRef]

30. Giovanardi, R.; Fontanesi, C.; Dallabarba, W. Adsorption of organic compounds at the aluminium oxide/aqueous solution interface during the aluminium anodizing process. Electrochim. Acta 2011, 56, 3128-3138. [CrossRef]

31. Fontanesi, C.; Benassi, R.; Giovanardi, R.; Marcaccio, M.; Paolucci, F.; Roffia, S. Computational electrochemistry. $\mathrm{Ab}$ initio calculation of solvent effect in the multiple electroreduction of polypyridinic compounds. J. Mol. Struct. 2002, 612, 277-286. [CrossRef]

32. Fontanesi, C. Theoretical study of the dissociative process of the 4-chlorotoluene radical anion. J. Mol. Struct. THEOCHEM 1997, 392, 87-94. [CrossRef]

33. Marcaccio, M.; Paolucci, F.; Fontanesi, C.; Fioravanti, G.; Zanarini, S. Electrochemistry and spectroelectrochemistry of polypyridine ligands: A theoretical approach. Inorg. Chim. Acta 2007, 360, 1154-1162. [CrossRef]

34. Pozio, A.; Masci, A.; Pasquali, M. Nickel-TiO2 nanotube anode for photo-electrolysers. Sol. Energy 2016, 136, 590-596. [CrossRef]

35. Kuang, Y.; Yamada, T.; Domen, K. Surface and interface engineering for photoelectrochemical water oxidation. Joule 2017. [CrossRef]

36. Rudolph, M.; Stanescu, D.; Alvarez, J.; Foy, E.; Kleider, J.-P.; Magnan, H.; Minea, T.; Herlin-Boime, N.; Bouchet-Fabre, B.; Hugon, M.-C. The role of oxygen in magnetron-sputtered Ta3N5 thin films for the photoelectrolysis of water. Surf. Coat. Technol. 2017, 324, 620-625. [CrossRef]

37. Gazzotti, M.; Arnaboldi, S.; Grecchi, S.; Giovanardi, R.; Cannio, M.; Pasquali, L.; Giacomino, A.; Abollino, O.; Fontanesi, C. Spin-dependent electrochemistry: Enantio-selectivity driven by chiral-induced spin selectivity effect. Electrochim. Acta 2018, 286, 271-278. [CrossRef]

Sample Availability: Samples of the compounds are not available from the authors.

(C) 2020 by the authors. Licensee MDPI, Basel, Switzerland. This article is an open access article distributed under the terms and conditions of the Creative Commons Attribution (CC BY) license (http://creativecommons.org/licenses/by/4.0/). 